\title{
An Extended Finite Element Method (XFEM) Study on the Elastic T-Stress Evaluations for a Notch in a Pipe Steel Exposed to Internal Pressure
}

\author{
Khadija Yakoubi ${ }^{1}$, Soufiane Montassir ${ }^{1}{ }^{(0)}$, Hassane Moustabchir ${ }^{2}$, Ahmed Elkhalfi $^{1}{ }^{(0)}$, \\ Catalin Iulian Pruncu $3,4, *$ (i) Jamal Arbaoui ${ }^{5}$ and Muhammad Umar Farooq ${ }^{6,7}$
}

check for

updates

Citation: Yakoubi, K.; Montassir, S.; Moustabchir, H.; Elkhalfi, A.; Pruncu, C.I.; Arbaoui, J.; Farooq, M.U. An Extended Finite Element Method (XFEM) Study on the Elastic T-Stress Evaluations for a Notch in a Pipe Steel Exposed to Internal Pressure. Mathematics 2021, 9, 507. https:// doi.org/10.3390/math9050507

Academic Editor: Krzysztof Kamil Żur

Received: 23 January 2021

Accepted: 22 February 2021

Published: 2 March 2021

Publisher's Note: MDPI stays neutral with regard to jurisdictional claims in published maps and institutional affiliations.

Copyright: (c) 2021 by the authors. Licensee MDPI, Basel, Switzerland. This article is an open access article distributed under the terms and conditions of the Creative Commons Attribution (CC BY) license (https:// creativecommons.org/licenses/by/ $4.0 /)$.
1 Faculty of Science and Technology, Sidi Mohamed Ben Abdellah University, Fez 30000, Morocco; khadija.yakoubi95@gmail.com (K.Y.); soufianemontassir@gmail.com (S.M.); aelkhalfi@gmail.com (A.E.)

2 Laboratory of Systems Engineering and Applications (LISA), National School of Applied Sciences of Fez, Sidi Mohamed Ben Abdellah University, Fez 30000, Morocco; hmoustabchir@hotmail.com

3 Department of Mechanical Engineering, Imperial College London, Exhibition Rd., London SW7 2AK, UK

4 Design, Manufacturing \& Engineering Management, University of Strathclyde, Glasgow G1 1XJ, UK

5 National School of Applied Sciences of Safi, University Cadi Ayad, Marrakesh 40000, Morocco; jamal57010@yahoo.fr

6 Department of Industrial and Manufacturing Engineering, University of Engineering and Technology, Lahore 54890, Pakistan; umarmuf0@gmail.com

7 Department of Industrial and Systems Engineering, Advanced Institute of Science and Technology (KAIST), Daejeon 34141, Korea

* Correspondence: c.pruncu@imperial.ac.uk or Catalin.pruncu@strath.ac.uk

\begin{abstract}
The work investigates the importance of the K-T approach in the modelling of pressure cracked structures. T-stress is the constant in the second term of the Williams expression; it is often negligible, but recent literature has shown that there are cases where T-stress plays the role of opening the crack, also T-stress improves elastic modeling at the point of crack. In this research study, the most important effects of the T-stress are collected and analyzed. A numerical analysis was carried out by the extended finite element method (X-FEM) to analyze T-stress in an arc with external notch under internal pressure. The different stress method (SDM) is employed to calculate T-stress. Moreover, the influence of the geometry of the notch on the biaxiality is also examined. The biaxiality gave us a view on the initiation of the crack. The results are extended with a comparison to previous literature to validate the promising investigations.
\end{abstract}

Keywords: T-stress; X-FEM; notch; pipe; stress difference method (SDM)

\section{Introduction}

In the field of fracture mechanics especially linear elastics, the vicinity of notch tip is often symbolized by singular stress entities. Their resistance is measured through stress intensity factor (SIF). The SIF is mainly depended on the distance $r$ from the tip of notch. In this field, parameter $\mathrm{T}$ is introduced to enrich the parameter $\mathrm{K}$ (SIF) to make the model better in the elastic stress field; this is the K-T approach [1].

In fracture mechanics body of knowledge, it is established that the same Stress Intensity Factor (SIF) is required for two cracks to propagate in the same way. Experiment [2] have shown that two plates with the same SIF and different crack length $a_{1}>a_{2}$ show different the propagation of the cracks. The results have shown that the propagation speed of $a_{2}$ is higher than that of $a_{1}$. The study concluded that the first term of asymptotic development is not sufficient to predict crack behavior. Therefore, it is necessary to increase the order. The first term asymptotic development is the SIF that determines the initiation and propagation of the crack. In addition, the second term is constant and controls the stability of the propagation direction. It is the transverse component symbolized by $\mathrm{T}$. 
Several studies have shown the significance of the T-Stress, and its influence on different parameters of mechanics. Jayadevan [3] highlighted that plastic zone is manipulated by the variation of T-stress. It means, the plastic area escalates with the increase in absolute value of T-stress and changes its form. Sobotka et al. [4] demonstrated the alteration in the plastic wake with many T-stresses which depends on plastic wakes height (HPW).

T-Stress has been an essential contributing factor in the stability of the direction of the crack propagation. For instance, $\mathrm{T}$ negative gives a stable direction, and for $\mathrm{T}$ positive it is unstable [5]. Fayed et al. [6] explored the impact of T-stress on propagating crack direction by Maximum Tangential Stress (MTS). The principle of MTS is that the crack propagates in the trend of maximum tangential stress. They obtained that the directions of the overall crack no coincide with the initial direction of the crack. Many studies have concluded the behavior by the fact that the tangential stress is affected by the T-Stress. MTS becomes generalized maximum tangential stress (GMTS), which considers the constraint $\mathrm{T}$ in the expression of stress. In the same context Shahani [1] studied the result on the initiating angle of propagating crack of the stress $T$. The study has shown a negative $T$ value declines the angle of crack initiation, and a positive T value enhances it. Nejati et al. [7] gauged the relationship between T-stress and material properties. Chen et al. [8] has shown that Graded Poisson's ratio affects the T-stress. Additionally, Toshio et al. [9] concluded that the Poison's ratio influences the T-stress on a three-dimensional edge-cracked plate.

Other important research that has shown the influences of the T-stress includes: Zhang et al. [10], which used numerical manifold method (NMM) is employed to calculate the T-stress for two-dimensional functionally graded material (FGM) having numerous cracks. Noritaka et al. [11] has resulted the T-stress might open micro-branches in the mist region. For the bending and tension load, Hancock [12] determined that $\mathrm{T}$ decreases with escalating crack length. Matvienko [13] explored the influence of T-stress in problems of the elastic and the elastic-plastic fracture mechanics.

Conventionally, the T-stress is often calculated at the crack tip, which is certainly not the case in this research. The research evaluates the T-stress at the tip of notch through extended finite element method (X-FEM).

The finite element method FE method is limited by the simple cases, as well as the presence of a singularity greatly degrades the convergence of the FEM. Belytschko and Blacken in 1999 added discontinuously enriching function in finite element approximation by respecting boundary conditions. Later, Moës et al. [14] developed the technique and called it as extended finite element method which is abbreviated as X-FEM. The efficiency of the X-FEM is well endorsed in the literature. To simulate the propagation of cracks in porous media, Wang et al. [15] integrated embedded discrete fracture method (EDFM) with X-FEM simulating fracture associated fluid and solid mechanics. Shu et al. [16] investigated the fatigue growth of 3-D multiple cracks by X-FEM. The implementation of X-FEM for composites resulted successfully [17-19]. X-FEM is also used for the calculation and analysis of failure mechanics parameters. Fakkoussi et al. [20] calculated stress intensity factor for mode one by X-FEM. Llavori et al. [21] studied the problems of contact fatigue by X-FEM.

The research study presents the use of X-FEM to calculate T-stress in the notch tip for an arc of the pipe of steel P264GH. Further, it demonstrates the benefits of using the X-FEM approach to compute $\mathrm{K}-\mathrm{T}$ at the notch point in an arc under pression and revealing the possibility of detecting the crack initiation.

The remaining article is organized as, Section 2 talks about the K-T approach, X-FEM, and the geometry used. Section 3 deals with the numerical result obtained, compared against FEM conclusions, along with the discussion. Finally, the conclusion is in the other section. 


\section{Materials and Methods}

\subsection{K-T Approach}

Stress Intensity Factor has been an essential parameter in the field of linear fracture mechanics, widely used for crack evaluation. SIF measures the strength of the singularity, and integrates various parameters such as load, geometry, and shape of crack. M. Hadj Meliani [22] suggested that a thin structure such as a thin pipe with a longitudinal crack, it is very difficult to characterize the stress field by a single parameter. For linear elasticity, the enrichment of the SIF with the T-stress is required to model the notch tip. In literature, studies show that $\mathrm{T}$ explains how geometry influences tenacity $\left(\mathrm{K}_{\mathrm{IC}}\right)$ [22]. T-stress helps in approximating the level of stress at a crack or tip of the notch. The possibility of constructing the $\mathrm{K}(\mathrm{T})$ curve numerically has given the opportunity to predict the loading of a crack initiation $[23,24]$. Including T-stress in calculations, it improves the prediction of propagating crack under the control of mixed loading. The K-T was additionally calculated for through-wall-cracked pipes under various pressure conditions by three dimension-3D FE [25]. The importance of the T-Stress is established in many works.

- T-stress enhances the possibility of crack opening stresses in the context of small crack [26];

$$
\sigma_{\mathrm{xx}}(\mathrm{r}, \theta)=\frac{\mathrm{K}_{1}}{\sqrt{2 \pi \mathrm{r}}} \mathrm{f}_{\mathrm{xx}}(\theta)+\mathrm{T}
$$

Taking $\sigma_{x x}(r, \theta)=\sigma_{c r}$, for the crack propagation, the first term tends to $\frac{K_{1}}{\sqrt{2 \pi r}} f_{x x}(\theta)$ to a because $\mathrm{K}_{1}=\mathrm{S}_{\mathrm{yy}} \sqrt{\pi \mathrm{a}}$, and if a tends to zero; the first term becomes negligible intheface to $\mathrm{T}$ at the crack point.

$$
\lim _{\mathrm{a} \rightarrow 0} \sigma_{\mathrm{xx}}(\mathrm{r}, \theta)=\sigma_{\mathrm{cr}}=\mathrm{T}
$$

In this case, the T-stress cannot be ignored, $\mathrm{T}$ play the role of crack opening, and therefore the importance of $\mathrm{T}$ varies with the size of the cracks.

- T-stress influences the plastic zone. Jayadevan [3] highlighted that plastic zone is affected by the variation of T-stress. The plastic area escalates with the upsurge in the absolute value of T-stress and changes its form. Sobotka et al. [4] demonstrated the deviation in the plastic wake with various T-stress which depends on plastic wakes height (hpw).

- Propagation's direction: Fayed et al. [6] analyzed the impact of T-stress on the propagation's direction by Maximum Tangential Stress (MTS). The principle of MTS is in the crack propagation direction which is in line with that of maximum tangential stress. MTS only considers the term singularity. Therefore, the direction of crack does not coincide with the initial directions of the crack. This behavior shows that the tangential stress is affected by the T-Stress. MTS becomes generalized maximum tangential stress (GMTS), which considers the T-stress in the expression of stress.

- T-stress has an impact on crack initiation angle. Shahani [1] analyzed the consequence of the T-stress on the angle of initiation of crack propagation. The study has shown that a negative $T$ value declines the angle of crack initiation, and a positive $T$ value enhances it.

- T-Stress is of prime significance when ensuring the stability of the direction of crack propagation, such as $\mathrm{T}$ negative gives a stable direction, and for $\mathrm{T}$ positive it is unstable [5].

T-Stress could be computed through numerous techniques. Weight Function Method has shown its efficiency in several problems cracking-related such as edge-cracked rectangular plate, circular disk [27]. Kfouri [28] developed a technique for evaluating the T-stress. The method uses the attributes of the path-independent J-integral and is called the Esheby-Integral method. 
The stress different method (SDM) has been proposed by Yang [29]. The idea of this method is the errors of the numerical values of $\sigma_{11}$ and $\sigma_{22}$ near a crack point progress with $\mathrm{r}$ in the same way, and the variation must effectively eliminate errors.

$$
\mathrm{T}=\sigma_{\mathrm{yy}}-\sigma_{\mathrm{xx}}
$$

Biaxiality is a parameter that relates the SIF and T-stress:

$$
\beta=\frac{\mathrm{T} \sqrt{\pi \mathrm{a}}}{\mathrm{K}}
$$

\subsection{Extended Finite Elements}

One of the uses of the FE method is the study of crack propagation but is limited for simple cases. If the mesh size does not conform to the crack, the FE method does not treat the propagation, and the presence of a singularity degrades the convergence of the FE method.

The solution is to add enrichment function to the FE approximation (see Figure 1); this is the extended finite element method.

$$
\mathrm{U}=\sum_{1}^{\mathrm{N}} \mathrm{N}_{\mathrm{i}} \mathrm{u}_{\mathrm{i}}+\sum_{\mathrm{i}}^{\mathrm{N}_{\text {saut }}} \mathrm{N}_{\mathrm{i}} \mathrm{H}(\mathrm{x}) \mathrm{a}_{\mathrm{i}}+\sum_{\mathrm{i}}^{\mathrm{N}_{\text {sing }}} \sum_{\mathrm{j}} \mathrm{N}(\mathrm{x})_{\mathrm{i}} \mathrm{F}(\mathrm{x})_{\mathrm{j}} \mathrm{b}_{\mathrm{i}}^{\mathrm{j}}
$$

where:

- $\mathrm{H}(\mathrm{x})$ : The Heaviside enrichment function, $\mathrm{H}(\mathrm{x})=\left\{\begin{array}{l}-1, \mathrm{x}>0 \\ +1, \mathrm{x}<0\end{array}\right.$

- $\quad \mathrm{F}(\mathrm{x})$ : Enrichment functions near the crack front.

- $\quad \mathrm{N}$ : Interpolation function of finite element. $\mathrm{N}_{\text {saut }}$ : Number of nodes enriched with Heaviside function. $\mathrm{N}_{\text {sin } g}$ : Number of knots enriched near the crack front.

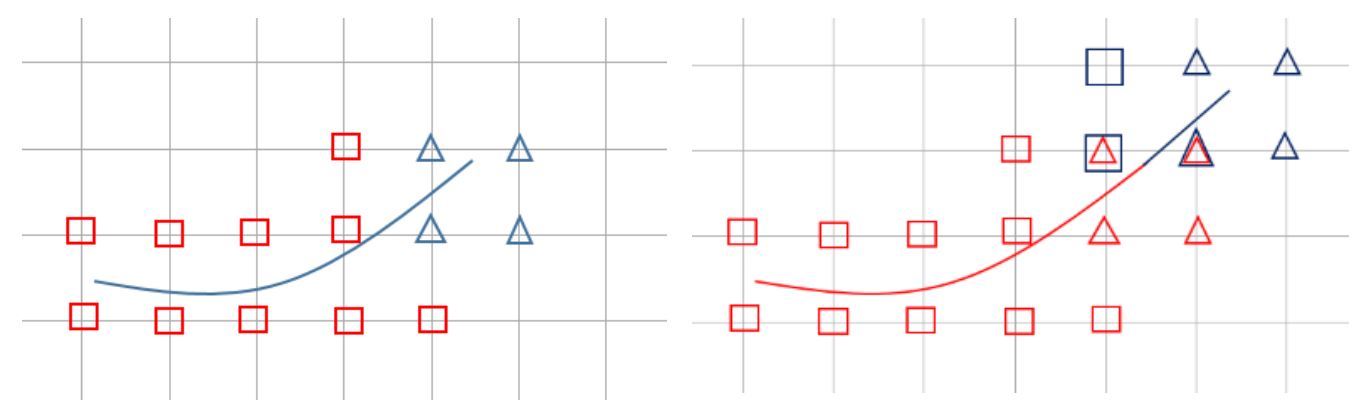

Figure 1. Step of enrichment methods.

The X-FEM requires operation to confirm the enrichment status of a knot according to its position in reference to the crack and to evaluate the functions $H(x)$ and $F(x)$. The position $(r, \theta)$ in relation to the notch point is calculated herein to know if $x$ is above or below the crack. These operations are carried out using the level sets method. The technique for describing crack is known as level set method. In the X-FEM, it determines the location of the crack and the crack point, and the position to apply discontinuous enrichment and enrichment to the crack point Figure 1. Most importantly, the level set provides an instant result that helps track crack propagation, i.e., as the crack propagates, enrichment at the crack front becomes discontinuous enrichment, and nodes (not enriched) become enriched. There are two-level functions, and the first describes the crack surface $(\varphi)$, second gives the crack front $(\psi)[30]$.

The X-FEM method was applied in several studies. Yousheng Xie et al. [31] have implemented the X-FEM method in the study of propagating crack in mixed mode, and evaluated the crack initiation angle. Reference [32] has shown the performance of the method. The study applied X-FEM to calculate SIF for 3D crack propagation problems 
for a Compact Tension C-T specimen. X-FEM was also implemented in the analysis of bi-material interfaces, calculating service life and fatigue resistance [33]. An integration between the X-FEM and embedded discrete fracture method (EDFM) is established for simulation of the process of fluid fracture propagation in porous media [15]. Savenkov et al. [34] employed the X-FEM to represent the central surface of the crack. The application of X-FEM for composite models is also carried out supporting current investigation [35,36].

X-FEM was used to predict components failure from a different form of notch [37]. Patria et al. [38] adopted X-FEM to study the mechanical attributes and fracture behavior of (Reinforced Polymeric Composites) RPC materials with single edge notch three-point bending.

\subsection{Geometry}

An arc of pipe containing a notch under pression was numerically analyzed using $\mathrm{X}$-FEM in ABAQUS software. The material used is a steel P264GH. The arc characterized by an inner radius $\mathrm{Ri}=219.55 \mathrm{~mm}$ and thickness $\mathrm{t}=6.1 \mathrm{~mm}$. More details on geometry, the shape of the notch, and boundary requirements used are illustrated in Figure 2 and Table 1.

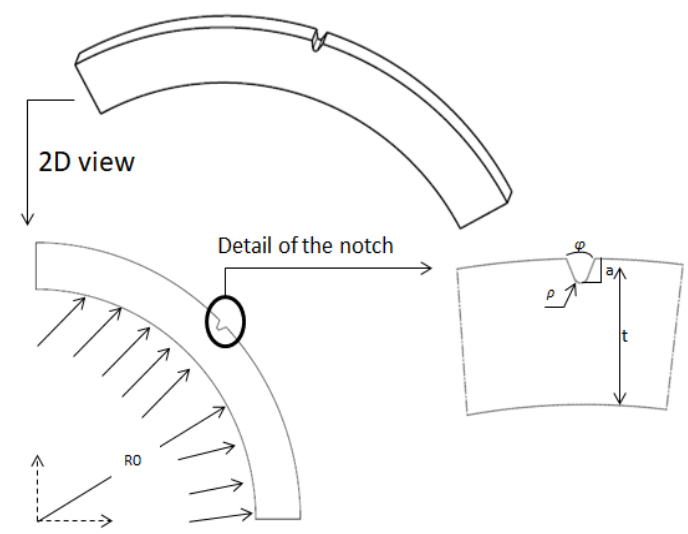

Figure 2. Details of the geometry and notch study, with boundary conditions.

Table 1. Geometry properties and load.

\begin{tabular}{cccccc}
\hline $\operatorname{Ri}[\mathrm{mm}]$ & $\mathbf{P}[\mathrm{MPa}]$ & $\boldsymbol{\varphi}[\mathrm{deg}]$ & $\mathbf{a}[\mathrm{mm}]$ & $\mathbf{t}[\mathrm{mm}]$ & $\rho[\mathrm{mm}]$ \\
\hline 213.45 & 15 & 45 & $1.22-4.88$ & 6.1 & 0.15 \\
\hline
\end{tabular}

The mechanical attributes of the material used are presented in Table 2, and the chemical composition of the material are included in Table 3.

Table 2. Mechanical characteristics of P264GH.

\begin{tabular}{cccc}
\hline Young's Modulus & Poisson's Ratio & Yield Stress & $\begin{array}{c}\text { Elongation to } \\
\text { Fracture }\end{array}$ \\
\hline $207,000 \mathrm{MPa}$ & 0.3 & $430 \mathrm{MPa}$ & $35 \%$ \\
\hline
\end{tabular}

Table 3. Chemical composition of P264GH.

\begin{tabular}{ccccccc}
\hline Material & C & Mn & S & Si & P & Al \\
\hline Tested & 0.135 & 0.665 & 0.002 & 0.195 & 0.027 & 0.027 \\
\hline $\begin{array}{c}\text { Steel P264GH } \\
\text { (Standard EN10028.2-92) }\end{array}$ & 0.18 & 1 & 0.015 & 0.4 & 0.025 & 0.02 \\
\hline
\end{tabular}

\section{Results}

This section presented the results of SIF and T-stress given by X-FEM via an user element UEL subroutine, the calculation was executed by ABAQUS software, we used 
quadratic element C3D20 in the mesh Figure 3, with a size of $0.5 \mathrm{~mm}$. The number of elements is 246117 . The number of nodes is 363256 .
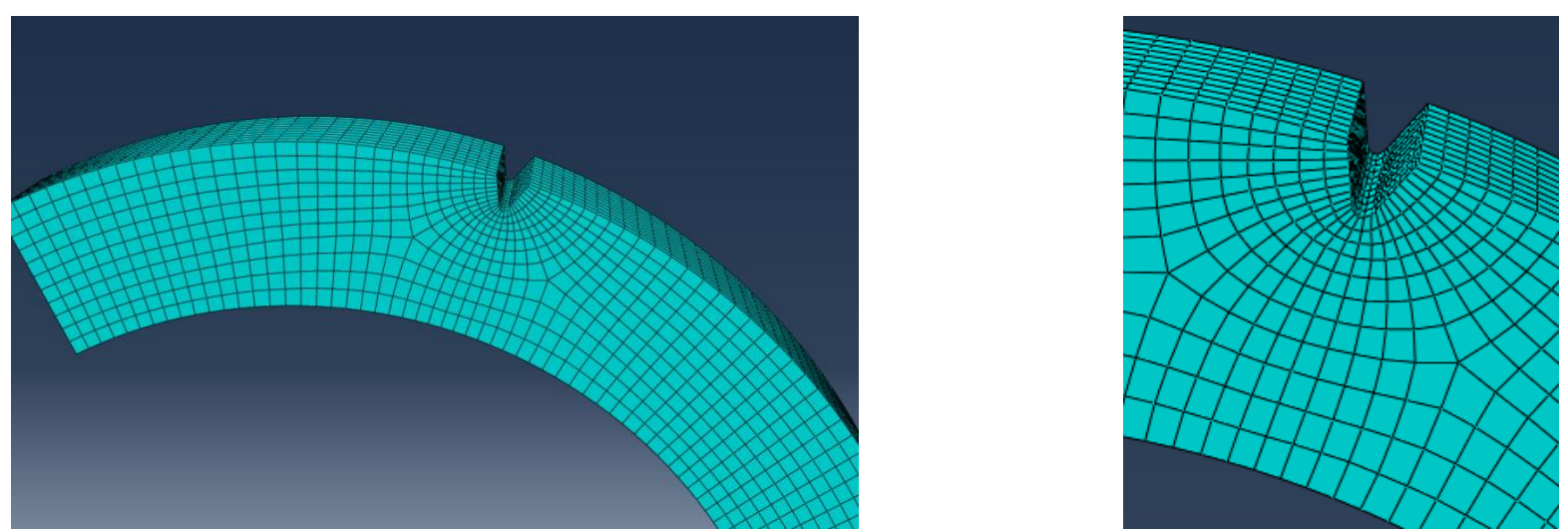

Figure 3. The mesh of 3D arc, C3D10 with $0.5 \mathrm{~mm}$ of size.

The T-stress is calculated through stress different method, and normalization is done for effect of the T-stress relative to the stress intensity factor by a parameter dimensionless termed biaxiality.

$$
\beta=\frac{\mathrm{T} \sqrt{\pi \mathrm{a}}}{\mathrm{K}}
$$

$\mathrm{K}$ is the value of stress intensity factor, and a is the notch length.

Figure 4 illustrates the difference of the SIF in mode 1 as a function of $r$, for $a / t=0.2$, by extended finite element.

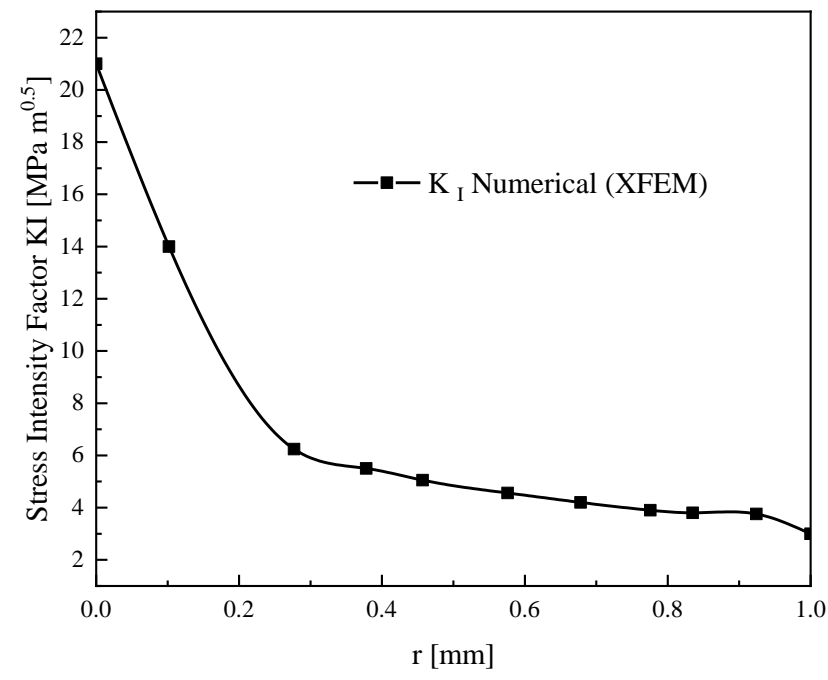

Figure 4. Distribution stress intensity factor SIF at the notch tip-SIF and $r$ for $a / t=0.2$.

The elastic SIF distribution at the notch tip decreases with distance from the tip of notch, for $\mathrm{a} / \mathrm{t}=0.2$ the maximum value of $\mathrm{SIF}$ is $21 \mathrm{MPa} \sqrt{\mathrm{m}}$ at notch tip, i.e., $r=0$ (see Figure 4). Near the notch tip SIF decreases rapidly to $6 \mathrm{MPa} \sqrt{\mathrm{m}}$ at $\mathrm{r}=0.3 \mathrm{~mm}$, then its variation becomes slower.

Figure 5 shows the variation of stress $\sigma_{x x}, \sigma_{y y}$ and T. T-stress increases with increasing $\mathrm{r}$ up to $\mathrm{r}=0.43$, and after that it starts to stabilize. The numerical calculation of the stress $\sigma_{x x}, \sigma_{y y}$ by X-FEM is executed by ABAQUS software. Figure 6 gives the Von Mises stress obtained by the Abaqus software. 


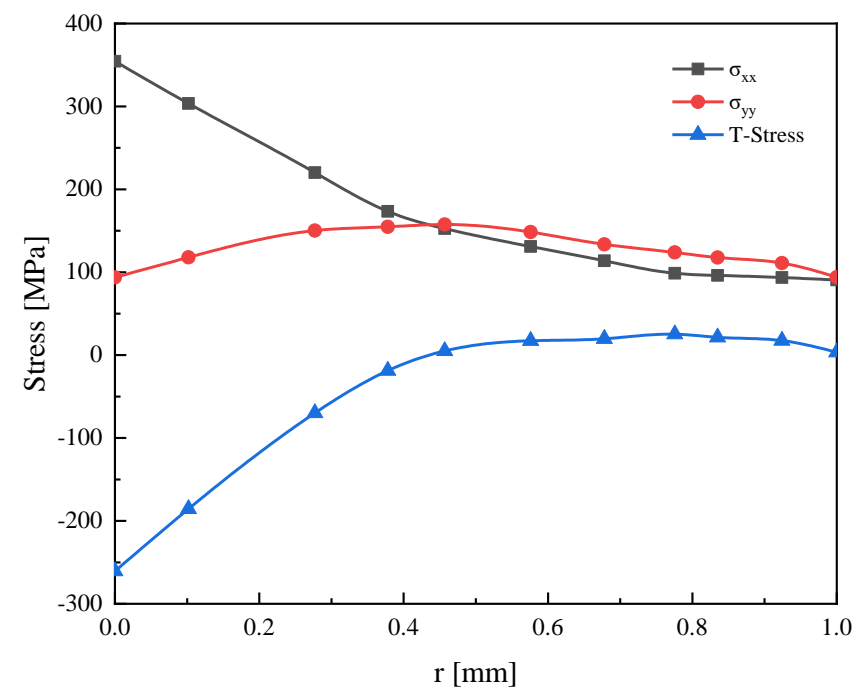

Figure 5. T-stress by stress different method.

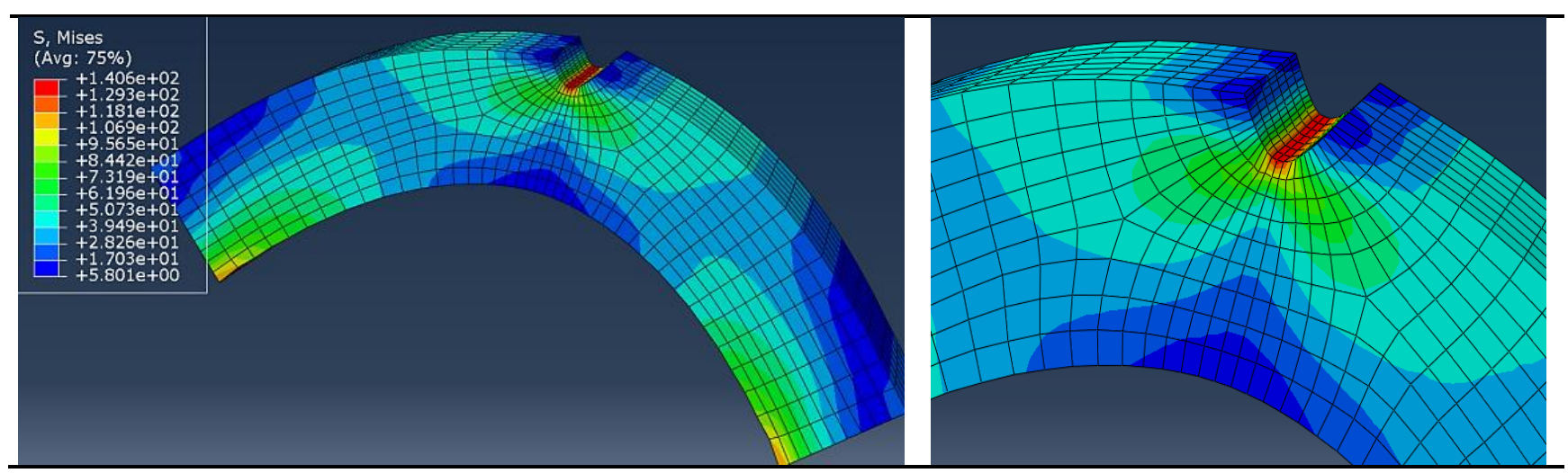

Figure 6. Distributions of Von Mises stress near the notch.

The result obtained of biaxiality are compared with H. Moustabchir [39], who calculated the biaxiality through the finite element method, for the same geometry which is used in this study. Figure 7 gives the variation of biaxiality as a function of $a / t$, by X-FEM and FEM.

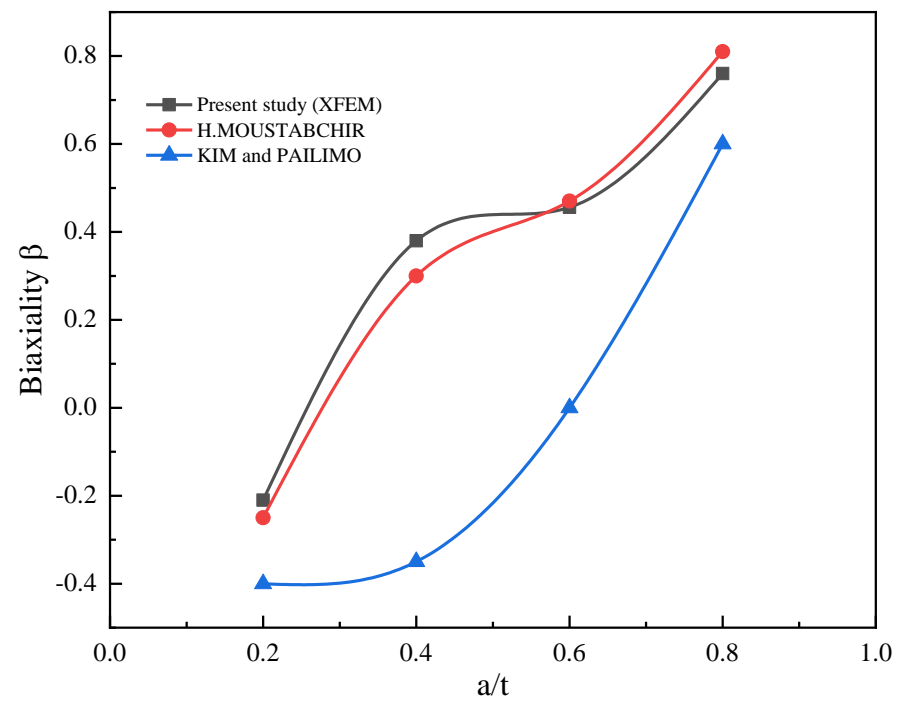

Figure 7. Variation of the biaxiality with $\mathrm{a} / \mathrm{t}$ at the notch. 
The biaxiality levels up with the increase $a / t$, The results are identical with the $H$. Moustabchir [39] recommendations. Kim and Paulino [40] has also got the same variation. By X-FEM the biaxiality varies from -0.21 to 0.76 for $\mathrm{a} / \mathrm{t}=0.2$ and 0.8 , respectively, and it goes from a positive to a negative value at $\mathrm{a} / \mathrm{t}=0.3$. The difference between the results given by $\mathrm{X}$-FEM and FEM is 0.013 .

\section{Discussion}

SIF measures the strength of the singularity, which explains the rapid variation of the SIF obtained for $r=[0,0.3]$. The more approach is made towards the notch tip, the more the stress concentration increases, and therefore, SIF increases. Moustabchir et al. [39] used the volumetric approach to calculate SIF, in the same condition that this research studied. Moustabchir et al. obtained for mode I at tip notch $\mathrm{K}_{1}=21.6 \mathrm{MPa} \sqrt{\mathrm{m}}$, which differs from our result by 0.5 . The T-stress can be analyzed by the SDM. The biaxiality increases with the rise in $\mathrm{a} / \mathrm{t}$, and the notch depth affects the value of T-stress. The same variation was obtained in other investigations on various materials. Bouchard et al. [41] have shown that $\mathrm{T}$ increases with increasing depth for a mono silicon. In [42], Sherry et al. obtained an increase in $\mathrm{T}$ in absolute value with the variation of the crack size over the width of a plate. In addition, Ayatollahi et al. [43] obtained for mode I, an increase in T-stress as a function of the depth of the crack for a single edge notched.

If

$$
\beta=1
$$

and

$$
\beta=\frac{T \sqrt{\pi \mathrm{a}}}{\mathrm{K}}
$$

So

$$
\mathrm{K}=\mathrm{T} \sqrt{\pi \mathrm{a}} \text { i.e., } \mathrm{T}=\sigma
$$

Which is not the case for this study $\beta_{\max }=0.78$, so $\mathrm{T} \neq \sigma$, which implies that $\mathrm{T}$ has no influence on the notch in our case and our condition.

Many studies have resulted that the influence of the T-stress is remarkable and significant when $\mathrm{T}$ is negative $[1,3,6]$, however, in this study for $\mathrm{r}<0.43$, negative T-stress causes an increase in the plastic zone [27]. This will cause a crack to initiate. In the presence of a crack, negative $\mathrm{T}$ can change the direction of propagating crack and decreases the crack growth initiation angle [31].

The K-T approach is an integration between the SIF and the T-stress to improve modelling the elastic stress at the point of the crack. The importance of T-stress has been highlighted, and it takes the place of short crack opening stress. Besides, the importance of the cooperation of SIF and T-stress, such as the $K(T)$ curve was elaborated which gives a prediction of the stress of crack initiation [44]. Neggaz et al. [44] studied the influences of the reinforcements in the structure of composites, with the aim of reducing constraints at notch-tip. Moreover, authors evaluated the effective stress intensity factors in the regard of propagating crack in thin and thick panels. Therefore, an Extended Finite Element Method (XFEM) is novel and improved technique on the elastic T-stress evaluations for a notch in a pipe steel exposed to internal pressure.

\section{Conclusions}

Three-dimensional Extended Finite Element (X-FEM) analysis is applied to evaluate the stress intensity factor and the T-stress for an arc of pipe with external notch under internal pressure. The results are presented below:

- To study the influence of geometry and notch size on the T-stress, authors have approached the biaxiality as a function of $a / t$. The evaluation endorsed that biaxiality $\beta$ increases with the increasing $a / t$ which is in accord with president results.

- The integration of biaxiality allowed us to determine the state of the crack initiation, and we can say that the pipe is safe in the used conditions. 
- The SIF alone does not characterize the behavior of notches. T-stress is obtained by Stress Difference Method (SDM) along with the notch in mode I. SDM is an efficient and simple method to calculate the fracture parameters.

- With ABAQUS-based investigations, the numerical results achieved by X-FEM are in good agreement with the Moustabchir result [39]. The implementation of X-FEM in the presence of a notch corrected the problems of the standard finite element method. The advantage of the X-FEM is that the mesh is independent of the notch.

For more precision, the future objective is to calculate the parameters of fracture mechanics by iso-geometrical analysis.

Author Contributions: Data curation, K.Y. and J.A., formal analysis, S.M. and A.E., investigation, H.M. and C.I.P., writing and review of original draft, M.U.F., H.M., and C.I.P. All authors have read and agreed to the published version of the manuscript.

Funding: This research received no external funding.

Institutional Review Board Statement: Not applicable.

Informed Consent Statement: Not applicable.

Data Availability Statement: The data that support the findings of this study are available on request from the corresponding author.

Acknowledgments: Authors are thankful to Aqib Mashood Khan for his constructive feedback.

Conflicts of Interest: The authors declare no conflict of interest.

\section{References}

1. Shahani, A.; Tabatabaei, S. Effect of T-stress on the fracture of a four point bend specimen. Mater. Des. 2009, 30, 2630-2635. [CrossRef]

2. Hamam, R.; Pommier, S.; Bumbieler, F. Mode I fatigue crack growth under biaxial loading. Int. J. Fatigue 2005, 27, 1342-1346. [CrossRef]

3. Jayadevan, K.; Narasimhan, R.; Ramamurthy, T.; Dattaguru, B. Effect of T-stress and loading rate on crack initiation in rate sensitive plastic materials. Int. J. Solids Struct. 2002, 39, 1757-1775. [CrossRef]

4. Sobotka, J.; Dodds, R. T-stress effects on steady crack growth in a thin, ductile plate under small-scale yielding conditions: Three-dimensional modeling. Eng. Fract. Mech. 2011, 78, 1182-1200. [CrossRef]

5. Cotterell, B.; Rice, J. Slightly curved or kinked cracks. Int. J. Fract. 1980, 16, 155-169. [CrossRef]

6. Fayed, A.S. Numerical Analysis of Crack Initiation Direction in Quasi-brittle Materials: Effect of T-Stress. Arab. J. Sci. Eng. 2019, 44, 7667-7676. [CrossRef]

7. Nejati, M.; Ghouli, S.; Ayatollahi, M.R. Crack tip asymptotic fields in anisotropic planes: Importance of higher order terms. Appl. Math. Model. 2021, 91, 837-862. [CrossRef]

8. Chen, X.; Yue, Z. Mode-I pressurized axisymmetric penny-shaped crack in graded interfacial zone with variable modulus and Poisson's ratio. Eng. Fract. Mech. 2020, 235, 107164. [CrossRef]

9. Toshio, N.; Parks, D.M. Determination of elastic T-stress along three-dimensional crack fronts using an interaction integral. Int. J. Solids Struct. 1992, 29, 1597-1611. [CrossRef]

10. Zhang, H.; Liu, S.; Han, S.; Fan, L. T-stress evaluation for multiple cracks in FGMs by the numerical manifold method and the interaction integral. Theor. Appl. Fract. Mech. 2020, 105, 102436. [CrossRef]

11. Nakamura, N.; Kawabata, T.; Takashima, Y.; Yanagimoto, F. Effect of the stress field on crack branching in brittle material. Theor. Appl. Fract. Mech. 2020, 108, 102583. [CrossRef]

12. Hancock, J.W.; Renter, W.G.; Parks, D.M. Constraint and Toughness Parameterized by T. In Constraint Effects in Fracture; Hackett, E., Schwalbe, K., Dodds, R., Eds.; ASTM International: West Concord, PA, USA, 1993; pp. 21-40.

13. Matvienko, Y. The effect of crack-tip constraint in some problems of fracture mechanics. Eng. Fail. Anal. 2020, 110, 104413. [CrossRef]

14. Moes, J.N.; Dolbow, T.B. A Finite Element Method for Crack Growth without Remeshing; John Wiley \& Sons, Ltd.: Hoboken, NJ, USA, 1999. [CrossRef]

15. Wang, C.; Huang, Z.; Wu, Y.-S. Coupled numerical approach combining X-FEM and the embedded discrete fracture method for the fluid-driven fracture propagation process in porous media. Int. J. Rock Mech. Min. Sci. 2020, 130, 104315. [CrossRef]

16. Shu, Y.; Li, Y.; Duan, M.; Yang, F. An X-FEM approach for simulation of 3-D multiple fatigue cracks and application to double surface crack problems. Int. J. Mech. Sci. 2017, 130, 331-349. [CrossRef]

17. Liang, Y.-J.; McQuien, J.S.; Iarve, E.V. Implementation of the regularized extended finite element method in Abaqus framework for fracture modeling in laminated composites. Eng. Fract. Mech. 2020, 230, 106989. [CrossRef] 
18. Akhondzadeh, S.; Khoei, A.; Broumand, P. An efficient enrichment strategy for modeling stress singularities in isotropic composite materials with X-FEM technique. Eng. Fract. Mech. 2017, 169, 201-225. [CrossRef]

19. Nagashima, T.; Suemasu, H. X-FEM analyses of a thin-walled composite shell structure with a delamination. Comput. Struct. 2010, 88, 549-557. [CrossRef]

20. El Fakkoussi, S.; Moustabchir, H.; Elkhalfi, A.; Pruncu, C.I. Computation of the stress intensity factor KI for external longitudinal semi-elliptic cracks in the pipelines by FEM and XFEM methods. Int. J. Interact. Des. Manuf. 2018, 13, 545-555. [CrossRef]

21. Llavori, I. A coupled crack initiation and propagation numerical procedure for combined fretting wear and fretting fa-tigue lifetime assessment. Theor. Appl. Fract. Mech. 2019, 101, 294-305. [CrossRef]

22. Meliani, H.M. Mécanique de la Rupture d'Entaille par l'Approche Globale: Estimation des Contraintes de Confinements dans des Structures Portant des Entailles; Editions Universitaires Européennes: Saarbrücken, Germany, 2010.

23. Anderson, T.L. Fracture Mechanics: Fundamentals and Applications; CRC Press LLC: Boca Raton, FL, USA, 2017.

24. Ravera, R.J.; Sih, G.C. Transient Analysis of Stress Waves around Cracks under Antiplane Strain. J. Acoust. Soc. Am. 1970, 47, 875-881. [CrossRef]

25. Yu, P.; Wang, Q.; Zhang, C.; Zhao, J. Elastic T -stress and I-II mixed mode stress intensity factors for a through-wall crack in an inner-pressured pipe. Int. J. Press. Vessel. Pip. 2018, 159, 67-72. [CrossRef]

26. Brugier, F. Modèle Condensé de Plasticité Pour la Fissuration et Influence de la Contrainte T; Université Paris-Saclay (ComUE): Saint-Aubin, France, 2017; Available online: https:/ / www.theses.fr/2017SACLN028 (accessed on 20 January 2021).

27. Gupta, M.; Alderliesten, R.; Benedictus, R. A review of T-stress and its effects in fracture mechanics. Eng. Fract. Mech. 2015, 134, 218-241. [CrossRef]

28. Kfouri, A.P. Some evaluations of the elastic T-term using Eshelby's method. Int. J. Fract. 1986, 30, 301-315. [CrossRef]

29. Yang, B.; Ravi-Chandar, K. Evaluation of elastic T-stress by the stress diøerence method. Eng. Fract. Mech. 1999, 64, 589-605. [CrossRef]

30. Du, Z. eXtended Finite Element Method (XFEM) in Abaqus; Simulia: Jhonston, RI, USA, 2009.

31. Xie, Y.; Cao, P.; Jin, J.; Wang, M. Mixed mode fracture analysis of semi-circular bend (SCB) specimen: A numerical study based on extended finite element method. Comput. Geotech. 2017, 82, 157-172. [CrossRef]

32. Yixiu, S.; Yazhi, L. A Simple and Efficient X-FEM Approach for Non-planar Fatigue Crack Propagation. Procedia Struct. Integr. 2016, 2, 2550-2557. [CrossRef]

33. Nasri, K.; Zenasni, M. Fatigue crack growth simulation in coated materials using X-FEM. Comptes Rendus Mécanique 2017, 345, 271-280. [CrossRef]

34. Savenkov, E.B.; Borisov, V.E.; Kritskiy, B.V. Surface Representation with Closest Point Projection in the X-FEM. Math. Model. Comput. Simul. 2020, 12, 36-52. [CrossRef]

35. Angioni, S.; Visrolia, A.; Meo, M. Combining X-FEM and a multilevel mesh superposition method for the analysis of thick composite structures. Compos. Part B Eng. 2012, 43, 559-568. [CrossRef]

36. Koutsawa, Y.; Belouettar, S.; Makradi, A.; Tiem, S. X-FEM implementation of VAMUCH: Application to active structural fiber multi-functional composite materials. Compos. Struct. 2012, 94, 1297-1304. [CrossRef]

37. Schiavone, A.; Abeygunawardana-Arachchige, G.; Silberschmidt, V.V. Crack initiation and propagation in ductile specimens with notches: Experimental and numerical study. Acta Mech. 2015, 227, 203-215. [CrossRef]

38. Patria, K.; Bambang, B.; Muhammad, F. XFEM Based Fracture Analysis of Single Notch Reactive Powder Concrete Specimen Subjected to Three Point Bending Test; Web of Conferences; EDP Sciences: Paris, France, 2020; p. 05027. [CrossRef]

39. Moustabchir, H.; Arbaoui, J.; Zitouni, A.; Hariri, S.; Dmytrakh, I. Numerical analysis of stress intensity factor and T-stress in pipeline of steel P264GH submitted to loading conditions. J. Theor. Appl. Mech. 2015, 53, 665-672. [CrossRef]

40. Kim, J.-H.; Paulino, G.H. T-stress, mixed-mode stress intensity factors, and crack initiation angles in functionally graded materials: A unified approach using the interaction integral method. Comput. Methods Appl. Mech. Eng. 2003, 192, 1463-1494. [CrossRef]

41. Bouchard, P.-O.; Bernacki, M.; Parks, D.M. Analysis of stress intensity factors and T-stress to control crack propagation for kerf-less spalling of single crystal silicon foils. Comput. Mater. Sci. 2013, 69, 243-250. [CrossRef]

42. Sherry, A.H.; France, C.C.; Goldthorpe, M.R. Compendium of t-stress solutions for two and three dimensional cracked geometries. Fatigue Fract. Eng. Mater. Struct. 1995, 18, 141-155. [CrossRef]

43. Ayatollahi, M.; Pavier, M.; Smith, D. Determination of T-stress from finite element analysis for mode I and mixed mode I/II loading. Int. J. Fract. 1998, 91, 283-298. [CrossRef]

44. Bouledroua, O.; Meliani, M.H.; Pluvinage, G. A Review of T-Stress Calculation Methods in Fracture Mechanics Computation. Nat. Technol. 2016, 11, 20. 